\title{
Pesquisa e produção intelectual na área de didática: resultados de um estudo múltiplo de casos $^{1}$
}

\author{
Letícia Brito Mendes Pimenta ${ }^{\mathrm{i}}$ \\ Universidade Federal do Triângulo Mineiro, Brasil \\ Orlando Fernández Aquinoii \\ Universidade de Uberaba, Brasil
}

\begin{abstract}
Resumo
Este trabalho buscou analisar o estado da pesquisa e produção didática, no período de 2004 a 2010, em três Programas de Pós-Graduação em Educação pertencentes à região Sul do Brasil, tomados como estudos de caso. Surgiu da análise de importantes estudos precedentes que mostraram um esvaziamento do campo teórico-científico da ciência didática. Com as informações levantadas, concluímos que os estudos sobre didática não são referência dentro das linhas da própria área. Pesquisa-se e se produz muito no campo investigativo e na dimensão dos fundamentos, mas as questões sobre ensino de didática enquanto disciplina acadêmica, bem como as formas e maneiras de se efetivar, do ponto de vista metodológico, o processo de ensino-aprendizagem, não estão sendo objeto de interesse.
\end{abstract}

Palavras-chave

Didática; Pesquisa e produção intelectual; Programas de Pós-Graduação em Educação

\section{Introdução}

A didática constitui-se como o principal ramo de estudos da pedagogia e a ela cabe o estudo dos processos de ensino-aprendizagem. Fornece aos professores todo o arcabouço necessário para o bom desempenho do 
processo educativo, atuando na mediação entre as bases teórico-científicas da educação escolar e a prática docente (Libâneo, 1992).

Sabemos que a didática oferece uma indiscutível contribuição à formação dos professores. Ao estudar questões relativas ao processo de ensino e aprendizagem, a didática oferece aos professores os conhecimentos específicos necessários para $\circ$ exercício da atividade docente. Consequentemente, o domínio apenas dos conteúdos específicos a serem ensinados não é suficiente para a formação dos professores (Libâneo, 2008b). Segundo Sguarezi (2010), como será possivel a formação de professores, como as pesquisas têm demonstrado que acontece, sem as contribuições da didática? A autora explica - e concordamos plenamente com suas considerações - que, se possuirmos como objetivo formar profissionais que sejam autônomos, responsáveis e autores de suas práticas pedagógicas, devemos criar as condições necessárias para que a didática ocupe uma posição de destaque na formação destes educadores. Sabendo então que ela é indispensável, não compreendemos como é que ela está desaparecendo, e este é um ponto fundamental a ser esclarecido, que esperamos entender melhor com os resultados de nossa pesquisa.

Os autores Puentes e Longarezi (2013, p. 10) defendem o conceito de 'didática desenvolvimental' e a definem como sendo uma ciência responsável por colocar em prática os processos que tratam dos objetivos da educação, da escola e também da pedagogia, que a teoria histórico-social defende. Também é responsável pela produção de novos conhecimentos no campo investigativo para ajudar a solucionar questões que ainda estão incertas, como é o caso do nosso problema investigado. Os autores acima mencionados expressam claramente uma completa definição de didática e suas relações:

A didática desenvolvimental, enquanto ciência interdisciplinar, vinculada à pedagogia, ocupa-se da organização adequada da atividade de ensinoaprendizagem-desenvolvimento, tendo o ensino intencional como seu objeto, a aprendizagem como condição e o desenvolvimento das neoformações e da personalidade integral do aluno estudante, especialmente do pensamento teórico, como objetivo (Puentes e Longarezi, 2013, p. 10).

Sendo assim, a didática desenvolvimental é fundamental para colaborar com as melhorias educacionais que tanto almejamos. É capaz de oferecer a estrutura para um processo de ensino-aprendizagem eficaz, 
preparando o aluno para que seja capaz de viver em sociedade e participar como sujeito ativo no meio social ao qual pertence. Para que isso seja possível, é necessário que inicialmente nos dediquemos às melhorias do processo de formação de professores, formando-os para uma didática desenvolvimental, reconhecendo sua importância na formação do sujeito e desenvolvimento psíquico.

Analisando agora o campo epistemológico da didática, algumas considerações são importantes. Libâneo (2010), em seu trabalho sobre $A$ integração entre didática e epistemologia: Uma via para a renovação dos conteúdos da didática, expõe que, para se obter as melhores condições de ensino, inicialmente é necessário saber como é que ocorre o processo de apropriação de conhecimentos, sendo que, para o autor, esta é uma questão puramente epistemológica. O autor também explica, no estudo acima citado, que é fundamental reconhecer que, para se sustentar a ideia de que toda a didática supõe uma epistemologia, devemos reconhecer, primeiramente, que o núcleo do problema didático é o conhecimento científico referente aos processos de ensino-aprendizagem.

Assim sendo, os arcabouços teóricos da pedagogia e da didática não são suficientes para entender o problema didático. Noutras palavras, a configuração do campo epistemológico da didática não pode se constituir sem as contribuições das ciências das quais derivam as disciplinas escolares, assim como de outras ciências afins como são a filosofia, a psicologia pedagógica, a neuropsicologia, a sociologia da educação, dentre outras ciências que colaboram na constituição do campo epistemológico da didática.

Para seu melhor estudo, o campo epistemológico da didática tem sido estruturado em três campos e três dimensões, lembrando que isso não constitui uma fragmentação do conhecimento elaborado historicamente por esta ciência. Todo o contrário, a estruturação do conhecimento didático em campos e dimensões obedece a uma organização sistêmica desse material, o que facilita tratar de abarcá-lo desde diferentes ângulos, com uma aspiração de totalidade, ainda que isso não seja objetivamente possível na sua integridade.

Longarezi e Puentes (2010) apresentam da seguinte maneira os campos para o estudo da didática: 
No Campo Disciplinar enquadraram-se os trabalhos que abordam e discutem questões relativas ao desenvolvimento da didática enquanto disciplina acadêmica, ou seja, relativas ao seu ensino; no Campo Profissional, trabalhos relacionados à formação e profissionalização para a docência com base nos saberes didáticos e no Campo Investigativo pesquisas que se ocupam do estudo do ensino, dos processos de ensino e aprendizagem, das relações entre ambos os processos, da prática docente e da produção de conhecimento novo sobre a didática (p. 4).

Apoiados em Libâneo (2008a), aqueles mesmos autores explicitam as dimensões da didática:

Os Fundamentos consistem no conjunto de saberes, conhecimentos, teorias, tendências, paradigmas, ideias, pensamentos, juízos, discursos, argumentos, etc. que obedecem a certas exigências de racionalidade e que são utilizados para justificar, explicar ou embasar as ações didáticas (as condições e os modos), incluindo-se ainda os estudos relacionados ao estado da arte. As Condições se enquadram em dois tipos: as externas (relacionadas à sociedade, comunidade, família, políticas educacionais, organização do trabalho pedagógico da escola, etc. que condicionam as práticas) e as internas ou relativas à organização do trabalho didático (ambiente educativo: espaço, tempo e recursos), os programas de aprendizagem e o papel educativo do processo docente. Os Modos incluem os objetivos, o sistema de conteúdos, os métodos, as atividades e estratégias de aprendizagem, bem como a avaliação, isto é, as formas e as maneiras de se efetivar do ponto de vista metodológico o processo de ensino-aprendizagem (Longarezi \& Puentes, 2010, p. 4).

Infere-se que os campos e dimensões da didática têm particular importância para os estudos sobre o estado atual das pesquisas e da produção intelectual nesta ciência, seja num sistema educativo, num estado ou região, num Programa de Pós-Graduação ou num grupo deles. Essa qualificação em campos e dimensões nos permitiu fazer numerosas correlações entre a pesquisa e a produção intelectual da área, fazer inferências e sugestões para a melhora da realidade educativa estudada.

Pesquisas recentes (Longarezi \& Puentes, 2010; Libâneo, 2010; Sguarezi, 2010) vêm mostrando que a didática está vivenciando um esvaziamento de seu campo teórico-científico, tanto na produção de novo conhecimento didático, como na sua presença na formação e desenvolvimento profissional dos professores, assim como no seu campo disciplinar, enquanto disciplina acadêmica. Porém, esses estudos não aprofundaram nos aspetos contextuais e institucionais que ajudassem na compreensão deste fenômeno. Sendo parte de uma equipe e projetos mais 
amplos, os estudos anteriores nos levaram a desenvolver uma pesquisa em três Programas de Pós-Graduação da região Sul do Brasil, assumidos como um estudo de casos múltiplos, buscando um maior entendimento do problema estudado.

Diante do exposto, o objetivo deste texto é apresentar uma análise do estado da pesquisa e da produção didática, no período de 2004 a 2010, em três Programas de Pós-Graduação em Educação pertencentes à região Sul do Brasil, tomados como estudos de caso. Além de mapear a situação da pesquisa e da produção intelectual na área, buscou-se também uma compreensão aprofundada da realidade estudada mediante o estudo de caso em que se constitui cada um desses Programas de Pós-Graduação. Sobre a seleção dos casos a serem estudados, utilizamos os critérios já elaborados pelos professores-pesquisadores que coordenam o projeto guarda-chuva em nível nacional2.

A coleta de dados foi realizada a partir de: fichas de avaliação trienal da CAPES, no período de 2004 a 2010, de cada um dos Programas estudados, disponíveis no site da CAPES; informações sobre os Programas, disponíveis nas suas respectivas páginas Web; e coleta de dados quantitativos sobre as pesquisas e produções desses Programas na base de dados www.pesquisasemeducacao.com.br. A qualificação dos dados da pesquisa e da produção intelectual, na área de didática, em campos e dimensões, na base de dados, bem como a classificação em ser ou não didática, foi realizada com a ajuda de um instrumento criado pelos pesquisadores do projeto nacional. Esse instrumento foi elaborado buscando uma sistematização do conceito de didática, assim como de seus campos e dimensões, visando proporcionar segurança na classificação e qualificação dos dados da pesquisa.

\section{Análises dos dados}

\section{Linhas de pesquisa e docentes por Programas}

Para compreendermos o estado da pesquisa e da produção didática nos Programas de Pós-Graduação em Educação que foram estudados, inicialmente é necessário uma análise das linhas de pesquisa e dos docentes dos Programas. Para tanto, o Gráfico 1 oferece uma sinopse referente ao total 
de linhas de pesquisa por Programas, comparadas com as avaliações trienais realizadas pela CAPES em 2007 e 2010. A seguir se realiza uma análise qualitativa desses dados.

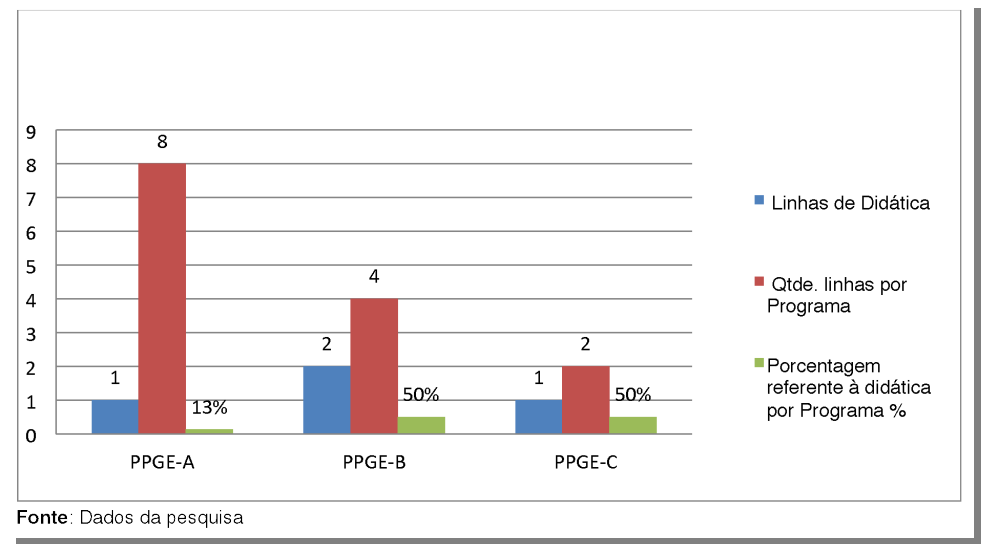

Gráfico 1 - Total de linhas de pesquisa e linhas de didática por Programas

Sobre a quantidade de linhas de pesquisa e de docentes dos Programas em estudo, verificamos, com os cortes de 2007 (2004 a 2006), 2010 (2007 a 2009) e 2012 (referente aos dados encontrados nas páginas dos Programas), que as linhas de pesquisa dos Programas, de uma forma geral, não sofreram muitas modificações, mas comparando os Programas entre si percebemos uma grande discrepância na importância que a didática ocupa entre eles.

No caso do Programa de Pós-Graduação em Educação da Universidade A (PPGE-A), a porcentagem de linhas de didática em relação ao total de linhas do Programa é de apenas 13\%, o que demonstra que os estudos referentes à ciência didática não são relevantes nesse Programa. Este Programa também apresenta uma grande quantidade de linhas de pesquisa, fato que a Comissão de Avaliação da CAPES até questiona; porém, dentre as oito linhas que possui, apenas uma se refere à didática, que é a linha "Ensino e formação de educadores". 
Descrevendo as linhas de pesquisa desse Programa, em relação aos triênios de 2007 e 2010 houve um aumento, passando de sete para nove linhas na avaliação trienal de 2010. Já em relação ao corte de 2012, que se refere às informações do site do Programa e que preenchem o gráfico acima, hoje este se estrutura em oito linhas de pesquisa.

Apesar das mudanças referentes às quantidades das linhas de pesquisa no PPGE-A, ainda persiste apenas a linha "Ensino e formação de educadores" que diz respeito aos estudos sobre didática. Infelizmente, este fato evidencia que, neste Programa, a pesquisa em didática é pouco relevante, e sabemos o quanto importante é sua utilização disciplinar na formação dos professores, já que oferece aos professores os conhecimentos específicos necessários para o exercício da atividade docente.

Já o Programa de Pós-Graduação em Educação da Universidade C (PPGE-C), analisado diante dos cortes de 2007 (2004 a 2006), 2010 (2007 a 2009) e 2012 (referente aos dados encontrados nas páginas dos Programas), mantém sua organização em torno de duas linhas de pesquisa. Dentre estas duas linhas, a linha "Práticas Pedagógicas: elementos articulares" se ocupa dos estudos sobre a didática, representando então $50 \%$ do total de linhas do Programa. Em virtude de este Programa ser composto apenas por duas linhas e uma delas se referir à didática, podemos dizer que, em relação ao PPGE-A, este se dedica melhor ao estudo da didática que o Programa estudado anteriormente.

Analisando agora o Programa de Pós-Graduação em Educação da Universidade B (PPGE-B), percebemos algumas mudanças em suas linhas de pesquisa no período do estudo. Compunha-se, na avaliação trienal de 2007, por cinco linhas; já na próxima avaliação trienal, esta quantia diminuiu para quatro e, destas, duas se ocupam dos estudos sobre didática, que são: "Formação, Saberes e Desenvolvimento Profissional" e "Currículo, Ensino e Práticas Escolares". Assim como no PPGE-C, 50\% das linhas do PPGE-B se ocupam da didática.

Comparando agora a quantidade atual de docentes dos Programas e suas quantidades nas linhas de didática, verificamos grande diferença entre cada um deles (Gráfico 2). 


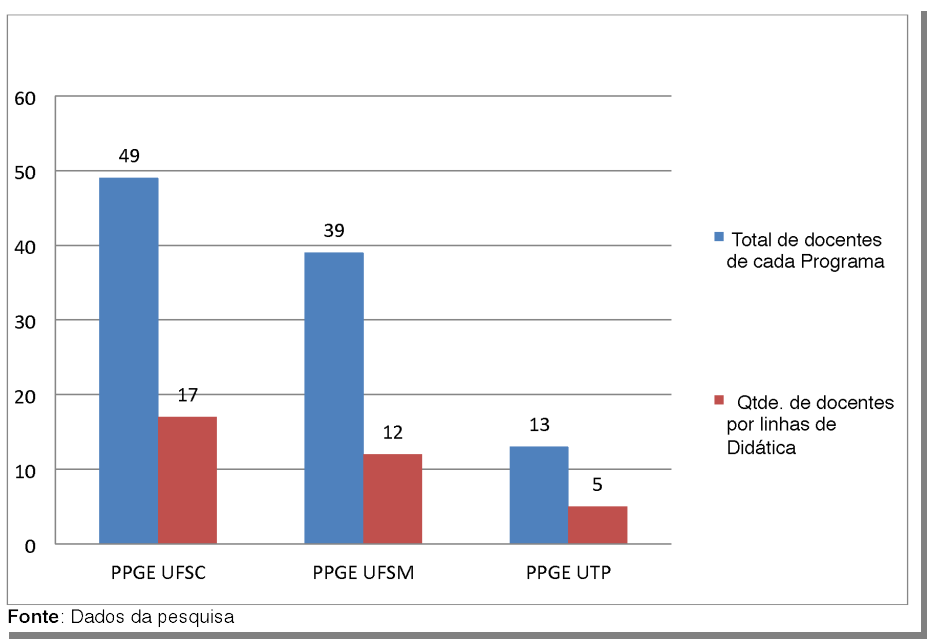

Gráfico 2 - Quantidade de docentes por Programas e linhas de didática

O Programa C, no final do triênio de 2007, possuía 19 docentes, sendo 15 permanentes. Já em 2010, este valor cai para 13 docentes, no total, sendo 12 permanentes. Apesar desta queda, o fato da maior parte destes pertencerem ao corpo permanente mostra, na avaliação de 2010, que não há dependência de docentes colaboradores. Com o corte de 2012, percebemos que não houve alteração do número total e, destes 13 docentes, 5 pertencem à linha de didática, evidenciando uma porcentagem de $38 \%$.

No PPGE-A, segundo a avaliação trienal de 2007, o Programa contava com um total de 47 professores, sendo 36 permanentes. Já na avaliação trienal de 2010 , esta quantia aumentou para 55 , com 46 pertencentes ao quadro permanente, diminuindo um pouco a dependência de docentes colaboradores. Apesar deste aumento dos docentes no segundo triênio, segundo as informações disponibilizadas no site do Programa, verificamos que atualmente o número total apresentou um decréscimo, diminuindo de 55 para 49 docentes, com 17 pertencentes à linha de didática, obtendo um percentual de $35 \%$.

Já o PPGE-B apresentou, ao longo dos anos, um aumento progressivo na quantidade de docentes. Ao final do primeiro triênio, contava com um total 
de 25, sendo que 23 deles eram professores permanentes. No final do segundo triênio estudado, o Programa aumentou este número para 33 e apenas 1 professor colaborador. Hoje, o Programa aumentou esse número para $39 \mathrm{e}$, deste total, 12 pertencem à linha de didática, obtendo um percentual de $31 \%$.

Concluindo as análises dos docentes e linhas de pesquisas dos três Programas, podemos verificar que o PPGE-C apresentou queda no número total de docentes, mas é importante considerar também que não há dependência de docentes colaboradores, e que entre os três Programas estudados é o que possui a porcentagem maior de total de docentes por linhas de pesquisa de didática. O PPGE-B vem gradativamente aumentando seu número de docentes, mas na comparação entre os casos este Programa obtém a menor porcentagem entre os três na relação quantidade de docentes e linhas de didática, com $31 \%$.

\section{Projetos de pesquisa nos PPGE em estudo}

Ao analisar o total de projetos de didática por Programas no período de 2004 a 2010, encontramos resultados diversos entre os Programas (Gráfico 3).

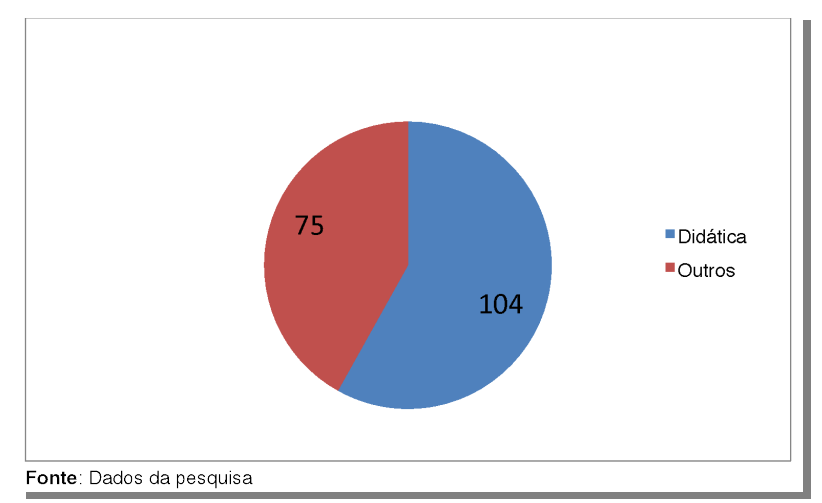

Gráfico 3 - Projetos das linhas de didática

Analisando inicialmente o total de projetos de pesquisa pertencentes a linhas de didática dos três Programas, conjuntamente (179), apenas 104 
$(58,10 \%)$ se referem à didática. Esse dado mostra que, apesar de existirem 179 projetos das linhas de didática, 75 não se referem ao estudo da didática. Ou seja, que, em certa medida, há professores que, apesar de estarem alocados nas linhas de didática, se dedicam à pesquisa de outros assuntos.

Em relação ao total de projetos desenvolvidos nas linhas de didática no PPGE-C, de um total de 18 projetos, 9 se referem à didática, evidenciando um percentual de 50\%. No caso do PPGE-A, existe um total de 49 projetos e 26 referentes à didática, obtendo então um percentual de 53,06\%. Já no PPGE-B, a quantidade de projetos é grande (112) e, destes, 69 tratam dos estudos sobre didática. Esse dado mostra que, nesse Programa, 61,61\% dos projetos das linhas de didática são realmente da área, o que Ihe confere uma característica peculiar, visto que a didática ocupa maior espaço em seus projetos de pesquisa (Tabela 1).

Tabela 1- Projetos de didática por Programas

\begin{tabular}{lccc}
\hline PROGRAMAS & $\begin{array}{c}\text { QTDE DE PROJETOS DAS } \\
\text { LINHAS DE DIDÁTICA }\end{array}$ & $\begin{array}{c}\text { PROJETOS } \\
\text { DIDÁTICA }\end{array}$ & $\%$ \\
\hline PPGE-A & 49 & 26 & $53,06 \%$ \\
PPGE-B & 112 & 69 & $61,61 \%$ \\
PPGE-C & 18 & 9 & $50,00 \%$ \\
TOTAL & $\mathbf{1 7 9}$ & $\mathbf{1 0 4}$ & $\mathbf{5 8 , 1 0 \%}$ \\
\hline Fonte: Dados da pesquisa & & &
\end{tabular}

Comparando os três Programas, casos de nossa pesquisa, podemos observar que é destaque o PPGE-B, com o maior percentual entre os três projetos de pesquisa referentes à didática. Analisando a quantidade total de projetos que as linhas de didática produzem e o total de projetos que correspondem à didática somando os três Programas, vimos que 58,10\% destes são didática. Esses dados nos mostram que, apesar de as linhas se referirem ao estudo de didática, ainda ocorre uma grande parte de projetos que não se referem à didática, o que é bastante controverso.

Observando agora os projetos de pesquisa por campos da didática, percebemos, entre os Programas estudados, vários pontos em comum (Tabela 2). Lembramos que o estudo dos campos e dimensões da didática é fundamental para a compreensão do estado atual das pesquisas e da 
produção intelectual nesta ciência. Através desta conceptualização podemos realizar numerosas correlações entre a pesquisa e a produção intelectual da área, fazer inferências e sugestões para a melhora da realidade educativa. 0 estudo de cada um desses campos e dimensões também contribui, de forma substancial, para fazer avançar a pesquisa, a formação de professores e a profissionalização docente na área de educação.

Tabela 2 - Projetos de pesquisa por campos da didática

\begin{tabular}{lccccccc}
\hline PROGRAMAS & $\begin{array}{c}\text { PROJETOS DE } \\
\text { DIDÁTICA }\end{array}$ & Investigativo & $\%$ & Disciplinar & $\%$ & Profissional & $\%$ \\
\hline PPGE-A & 26 & 23 & $88,46 \%$ & 0 & $0,00 \%$ & 3 & $11,54 \%$ \\
PPGE-B & 69 & 40 & $57,97 \%$ & 0 & $0,00 \%$ & 29 & $42,03 \%$ \\
PPGE-C & 9 & 9 & $100,00 \%$ & 0 & $0,00 \%$ & 0 & $0,00 \%$ \\
TOTAL & $\mathbf{1 0 4}$ & $\mathbf{7 2}$ & $\mathbf{6 9 , 2 3} \%$ & $\mathbf{0}$ & $\mathbf{0 , 0 0 \%}$ & $\mathbf{3 2}$ & $\mathbf{3 0 , 7 7 \%}$ \\
\hline Fonte: Dados da pesquisa & & & & & & &
\end{tabular}

Analisando a Tabela 2, verificamos que o campo investigativo é o mais estudado nos projetos de pesquisa dos Programas e o campo disciplinar não tem sido objeto de interesse em nenhum dos Programas. Merece destaque o fato de o PPGE-C apresentar todos os seus projetos no campo investigativo, o que mostra, conforme as definições dos campos já expostas, que os docentes desse Programa estão se preocupando exclusivamente com a produção de novos conhecimentos relacionados à prática docente e aos processos de ensino-aprendizagem. Conjuntamente, percebemos que o estudo da didática enquanto disciplina acadêmica não desperta interesse nesses Programas e os estudos de profissionalização para a docência com base nos saberes didáticos estão sendo pouco explorados.

Analisando agora os projetos de pesquisa dos três Programas em estudo por dimensões da didática, verificamos que os projetos do PPGE-A se concentram na dimensão das condições, revelando que os estudos preocupados com os condicionantes externos ou internos de realização da instrução e do ensino são responsáveis por $53,85 \%$ de seus projetos. Já os PPGE-C e B concentram seus projetos na dimensão dos fundamentos, mostrando que há predomínio de estudos visando à investigação do conjunto de saberes, ideias, conhecimentos, teorias, entre outros, que se constituem como a estrutura das fundamentações teóricas para o esclarecimento das 
ações didáticas. De forma conjunta, vimos que a dimensão dos fundamentos é a de maior interesse nas pesquisas e a dimensão dos modos, relacionada aos aspectos práticos da ciência didática, representa o menor interesse investigativo, sendo responsável por apenas 17,31\% (Tabela 3).

Tabela 3 - Projetos de pesquisa por dimensões da didática

\begin{tabular}{lccccccc}
\hline PROGRAMAS & $\begin{array}{c}\text { QUANTIDADE DE } \\
\text { PROJETOS }\end{array}$ & Fundamentos & $\%$ & Condições & $\%$ & Modos & $\%$ \\
\hline PPGE-A & 26 & 9 & $34,62 \%$ & 14 & $53,85 \%$ & 3 & $11,54 \%$ \\
PPGE-B & 69 & 31 & $44,93 \%$ & 23 & $33,33 \%$ & 15 & $21,74 \%$ \\
PPGE-C & 9 & 6 & $66,67 \%$ & 3 & $33,33 \%$ & 0 & $0,00 \%$ \\
TOTAL & 104 & 46 & $44,23 \%$ & 40 & $\mathbf{3 8 , 4 6 \%}$ & $\mathbf{1 8}$ & $\mathbf{1 7 , 3 1 \%}$ \\
\hline Fonte: Dados da pesquisal & & & & & & &
\end{tabular}

\section{A produção intelectual nos Programas de Pós-Graduação em estudo}

Partindo agora para a análise da produção intelectual na área de didática, por Programas, os PPGE-A, B e C, casos de nossa pesquisa, apresentam uma alta produção nas linhas relacionadas à didática; porém, nem mesmo $50 \%$ das produções das linhas de didática se referem realmente ao estudo de didática. No caso do PPGE-B, este apresenta o maior número total de publicações e, deste total, $43,33 \%$ são sobre didática, mostrando a relevância relativa que os estudos sobre didática representam para este Programa. Posteriormente, o PPGE-C concentra $32,75 \%$ de suas produções sobre didática e, após, o PPGE-A, com 29,72\%, que representa a menor porcentagem em relação ao total de produção sobre a didática (Tabela 4).

Tabela 4 - Produção didática por Programas

\begin{tabular}{lcccc}
\hline PROGRAMAS & $\begin{array}{c}\text { QTD. DOCENTES DAS } \\
\text { LINHAS SOBRE DIDÁTICA }\end{array}$ & $\begin{array}{c}\text { TOTAL DE } \\
\text { PRODUÇÕES }\end{array}$ & $\begin{array}{c}\text { PRODUÇÕES SOBRE } \\
\text { DIDÁTICA }\end{array}$ & PERCENTUAIS \\
\hline PPGE-A & 17 & 461 & 137 & $29,72 \%$ \\
PPGE-B & 12 & 944 & 409 & $43,33 \%$ \\
PPGE-C & 5 & 345 & 113 & $32,75 \%$ \\
TOTAL & 34 & $\mathbf{1 7 5 0}$ & 659 & $\mathbf{3 7 , 6 6 \%}$ \\
\hline Fonte: Dados da pesquisa & & & &
\end{tabular}


Analisando a produção englobando os três casos, para termos uma compreensão geral do que se produz de didática nestes Programas, temos um total de 1750 produções, divididas em artigos, livros, capítulos de livros e anais, e, deste total, apenas 659 são sobre didática, evidenciando uma porcentagem de $37,65 \%$.

Retomando as análises das fichas de avaliação segundo o quesito acima citado, o PPGE-C, que apresentava na primeira avaliação trienal considerada 223 produções bibliográficas qualificadas, aumentou este número, passando então para 350 em 2010. Este Programa também aumentou a quantidade de produções em periódicos internacionais. A média entre o total de produções do Programa e o total de docentes das linhas de didática nos dá uma relação de 69 produtos/docente, e, no caso da média entre a produção sobre didática e o total de docentes, essa relação é de 22,6 produtos/docente, um valor considerado razoável se comparado ao pequeno número de docentes deste Programa.

Analisando a produção intelectual do PPGE-A, percebeu-se uma diminuição nas publicações bibliográficas qualificadas entre os dois triênios. $\mathrm{Na}$ avaliação trienal de 2007, houve $97 \%$ dos docentes permanentes produzindo pelo menos 1 trabalho qualificado por ano; contudo, na avaliação trienal de 2010, esta porcentagem cai para $61 \%$ dos docentes permanentes publicando no mínimo 6 trabalhos qualificados. Esse dado mostra que as produções estão centralizadas em alguns docentes. Calculando a média entre o total de produções do Programa e a quantidade de docentes das linhas de didática, evidenciamos uma produção de 27,1 produtos/docente. Porém, ao realizarmos a média com as produções exclusivas sobre didática, vimos que essa relação cai 8,05 produções/docente.

No caso do PPGE-B, em relação a esse quesito ("Produção Intelectual"), houve, na avaliação trienal de 2007, um montante de 295 publicações bibliográficas qualificadas. Já na avaliação trienal de 2010, esse montante foi de 172 produtos em periódicos, 6 textos integrais de livros e 58 capítulos. Sobre a média do total de publicações por docente, este Programa possui 78,6 produtos/docente, e a média das publicações sobre didática por docente é de 34,08 produções/docente, bem maior que o PPGE-A.

Verificamos com esses dados que, apesar do PPGE-C ser recente e possuir uma quantidade bem menor de docentes em relação aos outros Programas, sua produção por docente é superior à do PPGE-A, Programa 
caracteristicamente consolidado. Também evidenciamos que o PPGE-B possui a maior média tanto no total de publicações por docente, como nas publicações sobre didática por docentes.

Partindo para a análise das produções intelectuais dos Programas por campos da didática, verificamos alguns resultados coincidentes com os projetos. O campo investigativo, assim como nos projetos de pesquisa, é predominante nos estudos de cada um dos casos de nossa pesquisa, como podemos ver mediante análise da Tabela 5. No PPGE-C, $85,84 \%$ de suas produções estão no campo investigativo; no PPGE-A, 66,42\%; e no PPGE-B esta porcentagem é de 75,31\%. Do total de produções dos três Programas, o campo investigativo representa um total de $75,27 \%$ referente a todas as produções, mostrando então a relevância que as produções sobre os processos pedagógicos e a produção de novos conhecimentos sobre a didática possui nesses Programas. Porém, o campo disciplinar é o que apresenta menos interesse investigativo nesses Programas, mostrando que ocorrem poucos estudos sobre a didática enquanto disciplina acadêmica e merecendo destaque o fato do PPGE-C não apresentar nenhuma produção neste campo. Comparando aos projetos, o PPGE-C, que apenas desenvolveu projetos no campo investigativo, nas produções ocorre uma mudança nesse panorama, passando agora a produzir também no campo profissional. Importante analisarmos também que o PPGE-A é o que mais produz no campo profissional, chegando a $32,12 \%$, apresentando, portanto, interesse nos trabalhos voltados para a formação e profissionalização para a docência.

Tabela 5 - Produção intelectual por campos da didática

\begin{tabular}{|c|c|c|c|c|c|c|c|}
\hline \multirow{2}{*}{ PROGRAMAS } & \multirow{2}{*}{ PRODUÇÃO DIDÁTICA } & \multicolumn{6}{|c|}{ CAMPOS DA DIDÁTICA } \\
\hline & & Investigativo & $\%$ & Disciplinar & $\%$ & Profissional & $\%$ \\
\hline PPGE-A & 137 & 91 & $66,42 \%$ & 2 & $1,46 \%$ & 44 & $32,12 \%$ \\
\hline PPGE-B & 409 & 308 & $75,31 \%$ & 2 & $0,49 \%$ & 99 & $24,21 \%$ \\
\hline PPGE-C & 113 & 97 & $85,84 \%$ & 0 & $0,00 \%$ & 16 & $14,16 \%$ \\
\hline TOTAL & 659 & 496 & $75,27 \%$ & 4 & $0,61 \%$ & 159 & $24,13 \%$ \\
\hline
\end{tabular}

Do total de produções das linhas de didática nos três Programas, $37,65 \%$ se referem à didática, mostrando que estas linhas produzem também muitos trabalhos que não são didática. 
Analisando agora as produções por dimensões da didática, observamos que a dimensão dos fundamentos é a mais investigada nos três Programas, demostrando um grande interesse nas fundamentações teóricas para explicar as ações didáticas. Nos projetos também houve predomínio da dimensão dos fundamentos nos PPGE-B e C, mas no PPGE-A a dimensão das condições é prevalente.

Por outro lado, a dimensão de menos interesse nas produções dos três Programas e casos de nossa pesquisa é a dimensão dos modos. Esse dado mostra que estudos sobre aspectos práticos da ciência didática - como os objetivos, sistema de conteúdos, métodos e estratégias de aprendizagem e avaliação - não estão sendo estudados como deveriam, pois sabemos sua importância para a melhoria dos processos educativos no país (Tabela 6).

Tabela 6 - Produção intelectual por dimensões da didática

\begin{tabular}{lccccccc}
\hline \multirow{2}{*}{ PROGRAMAS } & PRODUÇÃo DIDÁTICA & \multicolumn{7}{c}{ DIMENSÕES DA DIDÁTICA } \\
\cline { 2 - 8 } & & Fundamentos & $\%$ & Condições & $\%$ & Modos & $\%$ \\
\hline PPGE-A & 137 & 93 & $67,88 \%$ & 32 & $23,36 \%$ & 12 & $8,76 \%$ \\
PPGE-B & 409 & 271 & $66,26 \%$ & 90 & $22,00 \%$ & 48 & $11,74 \%$ \\
PPGE-C & 113 & 76 & $67,26 \%$ & 22 & $19,47 \%$ & 15 & $13,27 \%$ \\
TOTAL & $\mathbf{6 5 9}$ & $\mathbf{4 4 0}$ & $\mathbf{6 6 , 7 7 \%}$ & $\mathbf{1 4 4}$ & $\mathbf{2 1 , 8 5 \%}$ & $\mathbf{7 5}$ & $\mathbf{1 1 , 3 8} \%$ \\
\hline Fonte: Dados da pesquisa & & & & & & &
\end{tabular}

De uma forma geral, $66,77 \%$ das produções didáticas dos três Programas estão concentradas na dimensão dos fundamentos e a dimensão de menor interesse, de uma forma geral, é a dimensão dos modos.

Examinando agora os tipos de produção didática nos PPGE-A, B e C, verificamos que os anais são os veículos de maior publicação, chegando a $74,82 \%$ dos casos no PPGE-B (Tabela 7), mostrando que a maior parte das publicações ocorre em veículos de menor valoração. Já os veículos de menor publicação são os livros, também nos três Programas em estudo. As publicações no formato de artigos são, no caso do PPGE-C, mais expressivas do que nos outros Programas. Esse é um fato relevante, pois, como discutimos anteriormente, um Programa com uma pequena quantidade de docentes produz mais artigos que o PPGE-A, que apresenta um número três vezes maior de docentes relacionados à linha de didática. 
Tabela 7 - Produção didática por veículos de publicação

\begin{tabular}{lccccccccc}
\hline \multirow{2}{*}{ PROGRAMAS } & PRODUÇÃO & \multicolumn{7}{c}{ VEÍCULOS PUBLICAÇÃO } \\
\cline { 2 - 10 } & DIDÁTICA & Artigos & $\%$ & Livros & $\%$ & Cap. Liv. & $\%$ & Anais & $\%$ \\
\hline PPGE-A & 137 & 26 & $18,98 \%$ & 14 & $\mathbf{1 0 , 2 2 \%}$ & 32 & $23,36 \%$ & 65 & $47,45 \%$ \\
PPGE-B & 409 & 47 & $11,49 \%$ & 15 & $3,67 \%$ & 36 & $8,80 \%$ & 306 & $74,82 \%$ \\
PPGE-C & 113 & 27 & $23,89 \%$ & 4 & $3,54 \%$ & 11 & $9,73 \%$ & 70 & $61,95 \%$ \\
TOTAL & $\mathbf{6 5 9}$ & $\mathbf{1 0 0}$ & $\mathbf{1 5 , 1 7 \%}$ & $\mathbf{3 3}$ & $\mathbf{5 , 0 1 \%}$ & $\mathbf{7 9}$ & $\mathbf{1 1 , 9 9 \%}$ & $\mathbf{4 4 1}$ & $\mathbf{6 6 , 9 2 \%}$ \\
\hline Fonte: Dados da pesquisa & & & & & & & & &
\end{tabular}

Descrevendo as publicações em revistas Qualis dos Programas, percebemos que, de uma forma geral, as publicações também não estão centradas dentro das revistas de maior valoração ${ }^{3}$. No caso do PPGE-A, analisando as publicações dos dois triênios conjuntamente, vemos que, de um total de 26 artigos sobre didática, apenas 2 foram publicados em periódico $A 1$, ao passo que a maior publicação ocorreu nos periódicos $B 4$, que atingiu $34,62 \%$ do total. Quando comparamos ao triênio de 2010, onde o percentual de docentes permanentes com, no mínimo, 3 produtos qualificados com periódicos até B2 foi de $68 \%$, vemos que, de uma forma geral, este Programa não publica muito nas revistas de maior valoração, dentro do período do estudo.

O PPGE-B possuía $77 \%$ dos docentes permanentes publicando no mínimo 2 produtos (para os docentes do mestrado) e 3 produtos (para os docentes do doutorado) até B2 no triênio de 2010. Analisando os dois triênios conjuntamente, percebemos que este Programa apresenta a maior parte de seus trabalhos de didática publicados em periódicos B2 e B4.

Já no PPGE-C, na avaliação trienal de 2010, o percentual de docentes permanentes com, no mínimo, 2 produtos veiculados em periódicos até B2 foi de $90 \%$, sendo avaliado com conceito "Muito Bom" pela Comissão de Avaliação. A análise conjunta dos dois triênios mostra-nos que este Programa publica $37,04 \%$ do total de seus artigos em revistas B1 e a mesma porcentagem em revistas $\mathrm{B} 3$.

Procedendo à análise das publicações em livros por editoras, os dados encontrados através da mineração na base de dados, referente ao período de 2004 a 2010, nos mostram que as editoras nacionais são prevalentes nas publicações de livros nos PPGE-B e C. Porém, no PPGE-B ocorre certo equilíbrio entre as editoras nacionais e outras. Outro fato importante é que não 
há publicações de livros de didática por editoras internacionais em nenhum dos Programas em estudo (Tabela 8).

Tabela 8 - Publicações em livros por tipos de editora

\begin{tabular}{|c|c|c|c|c|c|c|c|c|c|}
\hline \multirow{3}{*}{ Programas } & \multicolumn{8}{|c|}{ Livros por tipo de Editora } & \multirow{3}{*}{ Total } \\
\hline & \multicolumn{2}{|c|}{ Editoras Internacionais } & \multicolumn{2}{|c|}{ Editoras Nacionais } & \multicolumn{2}{|c|}{ Editoras Universitárias } & \multicolumn{2}{|c|}{ Outras Editoras } & \\
\hline & $\mathrm{N}^{\circ}$ & $\%$ & $\mathrm{~N}^{\circ}$ & $\%$ & $\mathbf{N}^{\circ}$ & $\%$ & $\mathrm{~N}^{\circ}$ & $\%$ & \\
\hline 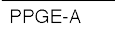 & 0 & $0,00 \%$ & 5 & $35,71 \%$ & 3 & $21,43 \%$ & 6 & $42,86 \%$ & 14 \\
\hline PPGE-B & 0 & $0,00 \%$ & 8 & $53,33 \%$ & 0 & $0,00 \%$ & 7 & $46,67 \%$ & 15 \\
\hline PPGE-C & 0 & $0,00 \%$ & 3 & $75,00 \%$ & 0 & $0,00 \%$ & 1 & $25,00 \%$ & 4 \\
\hline
\end{tabular}

Por último, analisando as publicações em anais por tipo de evento (Tabela 9), verificamos que estes são apresentados em eventos diversos nos três Programas. No PPGE-A, estes são apresentados, em sua maior parte, em eventos nacionais e regionais, seguidos pelos internacionais. No PPGE$B$, as publicações dos anais ocorrem preferencialmente em eventos nacionais, nos dois triênios. No caso do PPGE-C, as apresentações de anais em eventos locais e nacionais são próximas, com 31,43\% e 34,29\%, analisando de uma forma geral os dois triênios; mas, individualizando o triênio de 2007, este tipo de publicação acontecia preferencialmente em eventos nacionais e internacionais. Vale ressaltar que o PPGE-C, mais recente, entre os três, é o que mais apresenta anais em eventos internacionais.

Tabela 9 - Publicações em anais por tipo de evento

\begin{tabular}{|c|c|c|c|c|c|c|c|c|c|c|c|}
\hline \multirow{3}{*}{ Programas } & \multicolumn{10}{|c|}{ Congressos } & \multirow{3}{*}{ Total } \\
\hline & \multicolumn{2}{|c|}{ Internacional } & \multicolumn{2}{|c|}{ Nacional } & \multicolumn{2}{|c|}{ Regional } & \multicolumn{2}{|r|}{ Local } & \multicolumn{2}{|c|}{ Outros } & \\
\hline & $\mathbf{N}^{\circ}$ & $\%$ & $\mathrm{~N}^{\circ}$ & $\%$ & $\mathbf{N}^{\circ}$ & $\%$ & $\mathrm{~N}^{\circ}$ & $\%$ & $\mathrm{~N}^{0}$ & $\%$ & \\
\hline PPGE-A & 18 & $27,69 \%$ & 25 & $38,46 \%$ & 22 & $33,85 \%$ & 0 & $0,00 \%$ & 0 & $0,00 \%$ & 65 \\
\hline PPGE-B & 73 & $23,86 \%$ & 147 & $48,04 \%$ & 53 & $17,32 \%$ & 33 & $10,78 \%$ & 0 & $0,00 \%$ & 306 \\
\hline PPGE-C & 19 & $27,14 \%$ & 24 & $34,29 \%$ & 5 & $7,14 \%$ & 22 & $31,43 \%$ & 0 & $0,00 \%$ & 70 \\
\hline
\end{tabular}

Ao analisarmos estas publicações em anais, podemos concluir, de forma bastante genérica, que as publicações nos eventos nacionais ocupam destaque, mas as publicações internacionais estão aumentando nos PPGE-C e $B$, ao contrário do PPGE-A, que apresentou um decréscimo quando comparamos os dados das fichas de avaliações trienais estudadas. 
Por fim, cada Programa possui uma história e características singulares. Esta análise nos possibilita, entretanto, fazer algumas afirmações. Entre os três casos estudados, o PPGE-B se destaca praticamente em todos os aspectos. No período do estudo, aumentou sua quantidade de docentes, seus projetos e suas publicações, e merece atenção o fato de que é o Programa que mais pesquisa e produz sobre didática, entre os três. O PPGE$\mathrm{C}$, apesar de pequeno em comparação aos outros, também progrediu no período do estudo. Reduziu sua quantidade de docentes, mas este fato não impediu que o Programa se fortalecesse e conseguisse a melhora em todos os quesitos analisados pela Comissão de Avaliação da CAPES. Já o PPGEA apresentou um decréscimo neste período, de 2004 a 2010, devido ao fato da queda na produção bibliográfica docente e discente e também pela desigualdade na distribuição dos docentes pelas linhas de pesquisa. É importante salientar também que é no PPGE-A que menos se pesquisa sobre didática, nos casos estudados, apesar de ser o Programa com a maior quantidade de docentes nas linhas de didática.

\section{Considerações finais}

Verificamos, através do estudo de cada um destes Programas, que ocorrem muitas pesquisas e produções no campo investigativo e no campo profissional. Porém, não ocorrem projetos no campo disciplinar e as produções deste campo ocorrem em quantias ínfimas. Isso mostra a preocupação com os aspectos relacionados ao estudo da produção de conhecimento novo sobre didática, bem como os processos de ensinoaprendizagem e prática docente, e a pouca atenção sobre o ensino de didática enquanto disciplina acadêmica e suas contribuições para a formação do professor. Sobre as dimensões, tanto as pesquisas como as produções ocorrem preferencialmente na dimensão dos fundamentos, dando ênfase, então, aos aspectos teóricos da realização da instrução e do ensino. A dimensão dos modos, que diz respeito aos meios, recursos e técnicas utilizadas no processo de ensino-aprendizagem, também é pouco explorada.

Através deste estudo evidenciamos que os PPGE acima citados estão pesquisando e produzindo relativamente bem, mas os estudos sobre didática não são a referência nas próprias linhas de pesquisa da área, principalmente no caso das produções. Sobre os projetos de pesquisa, dos três Programas, das linhas referentes à didática, observamos, de forma conjunta, que apenas 
$58,10 \%$ deles se referem à didática, e nas produções a situação é ainda pior, com apenas $37,65 \%$. Infelizmente, esses dados confirmam - assim como nos PPGE do estado de Minas Gerais, conforme estudo de Longarezi e Puentes (2010) - que a didática não é referência nos estudos das linhas de didática, nos Programas estudados, e que, da mesma forma, a dimensão dos modos não é estudada como deveria, senão que a ênfase é colocada nos aspectos teóricos. Sabemos que os estudos teóricos são importantes, mas necessitamos de muito além para que possamos vivenciar as tão esperadas melhorias nos processos de ensino-aprendizagem.

Por fim, percebemos que se pesquisa e se produz muito, no campo investigativo, na dimensão dos fundamentos, mas o campo disciplinar, assim como a dimensão dos modos, estão sendo esquecidos. Provavelmente, nestes professores-pesquisadores não há muita compreensão de que uma boa formação didático-pedagógica dos professores faria progredir a qualidade dos processos de ensino e aprendizagem e que isso seria uma grande contribuição para a educação no país. O campo profissional, também fundamental nessa direção, deveria ser mais explorado. É necessário que os docentes se dediquem aos estudos referentes às linhas que ocupam no sentido de que consigam desenvolver trabalhos que atendam às diversas necessidades que a nossa educação precisa para ser melhorada. Concentrar as pesquisas e produções em alguns aspectos e ignorar outros não conseguirá trazer os benefícios que tanto almejamos para termos uma educação de qualidade. Se não se pesquisa e se publica sobre a prática pedagógica na sala de aula, especialmente sobre os modos e as condições de efetivar o processo de ensino-aprendizagem, dificilmente haverá transformações concretas na qualidade da aprendizagem dos alunos. Esta pesquisa nos mostra o quanto ainda se precisam ajustar as políticas de pesquisa e produção intelectual nos Programas de Pós-Graduação em Educação no Brasil.

\section{Notas}

1 Este trabalho faz parte de um projeto guarda-chuva intitulado "A didática no âmbito da Pós-Graduação na região Sul do Brasil: uma análise das pesquisas e produções no período de 2004 a 2010", financiado pelo Programa PAPE-FAPEMIG-UNIUBE, processo 007/2011. Por sua vez, o dito projeto é um subprojeto do projeto interinstitucional intitulado "A didática no âmbito da Pós-Graduação no Brasil: uma 
análise das pesquisas e produções no período de 2004 a 2010", financiado por CNPq (Edital MCT/CNPq/MEC/CAPES n 02/2010).

2 Estes critérios são: 1) Garantir a representatividade dos Programas, de acordo com a CAPES; 2) Que sejam programas credenciados pela CAPES; 3) Que os Programas disponham de linhas de pesquisa relacionadas à Didática ou áreas afins; 4) Que os Programas tenham cursos de Mestrado e Doutorado; 5) Que o conceito da última avaliação junto a CAPES seja igual ou superior a 4 em ambos os cursos; 6) Que o tempo de credenciamento junto à CAPES seja critério para definir a seleção dos Programas (Longarezi, 2010, p. 8).

3 Segundo o WebQualis (http://qualis.capes.gov.br/webqualis), o Qualis Periódicos está dividido em oito estratos, em ordem decrescente de valor, sendo eles: A1, A2, B1, B2, B3, B4, B5 e C. Os quatro primeiros estratos ficaram assim classificados: A1- Fator de Impacto igual ou superior a 3,800; A2 - Fator de Impacto entre 3,799 e 2,500; B1- Fator de Impacto entre 2,499 e 1,300; B2 - Fator de Impacto entre 1,299 e 0,001. Para ser incluído nos quatro estratos superiores, o periódico deve ter fator de impacto medido pelo Institute for Scientific Information(ISI). A classificação de um periódico em cada um desses estratos baseia-se em alguns princípios: a posição do periódico na escala depende do seu fator de impacto; o número de periódicos A1, que é o estrato superior da escala, deve ser inferior ao de A2; a soma de $\mathrm{A} 1$ + A2 deve corresponder a, no máximo, $26 \%$ dos periódicos em que a área publicou artigos no triênio anterior; A1 + A2 + B1 não pode ultrapassar $50 \%$ de todos os periódicos do triênio anterior. O indicador para classificar os periódicos B3, B4 e B5 (que não possuem fator de impacto) é a base de dados em que os mesmos estão indexados. Já os periódicos irrelevantes para a área são classificados no estrato $\mathrm{C}$ e não receberão pontuação.

\section{Referências}

Libâneo, J. C. (1992). Didática. São Paulo: Cortez.

Libâneo, J. C. (2008a). Didática e epistemologia: Para além do embate entre a didática geral e as didáticas específicas. In I. P. A. Veiga \& C. D’Ávila (Orgs.). Profissão docente: Novos sentidos, novas perspectivas. Campinas: Papirus Editora.

Libâneo, J. C. (2008b). O campo teórico e profissional da didática hoje: Entre Ítaca e o campo das sereias. In E. Eggert, C. Traversini, E. Peres \& I. Bonin, Trajetórias e processos de ensinar e de aprender (pp. 234-252). Porto Alegre: Edipucrs.

Libâneo, J. C. (2010). O ensino de didática, de metodologias específicas e de conteúdos do Ensino Fundamental: $O$ caso dos cursos de pedagogia no estado de Goiás. In Anais do XV ENDIPE - Encontro Nacional de Didática e Prática de Ensino (pp. 14-26). Belo Horizonte: Editora Autêntica.

Longarezi, A. M. (2010). A didática no âmbito da Pós-Graduação no Brasil: Uma análise das pesquisas e produções no período de 2004 a 2010 (Projeto interinstitucional de pesquisa, Edital MCT/CNPq/MEC/CAPES n 02/2010). 
Longarezi, A. M., \& Puentes, R. V. (2010). O lugar da didática nas pesquisas e produções dos Programas de Pós-Graduação em Educação do Estado de Minas Gerais/BR. In Anais do XV ENDIPE - Encontro Nacional de Didática e Prática de Ensino, v. 1 (pp. 2-14). Belo Horizonte: Editora Autêntica.

Puentes, R. V., \& Longarezi, A. M. (2013). Escola e didática desenvolvimental: Seu campo conceitual na tradição da teoria histórica. Educação em Revista, Vol. 29. DOI: $10.1590 / S 0102-46982013005000004$.

Sguarezi, N. O. (2010). As abordagens da didática nos cursos de formação de professores: O caso da Universidade Federal de Mato Grosso. In Anais do XV ENDIPE - Encontro Nacional de Didática e Prática de Ensino, v. 1 (pp. 27-39). Belo Horizonte: Editora Autêntica. 
RESEARCH AND DIDACTIC PRODUCTION: RESULTS OF A STUDY OF MULTIPLE CASES

Abstract

This paper aimed at analyzing the state of the research and didactic production, between 2004 and 2010, in three Graduate Programs in Education southern Brazil, taken as case studies. It emerged from important previous studies that showed a decrease of the theoretical-scientific field of the science of didactic. With the collected information we concluded that the studies about didactic are not reference within the lines of its own area. It is abundantly researched and produced in the investigative field and in the dimension of the fundaments, but the questions about the teaching of didactic while an academic subject, as well as from the methodological point of view the forms and manners of doing, the process of teaching and learning, are not being object of interest.

Keywords

Didactic; Research and intellectual production; Graduate Programs in Education

INVESTIGACIÓN Y PRODUCCIÓN EN EL ÁREA DE DIDÁCTICA: RESULTADOS DE UN ESTUDIO DE CASOS MÚLTIPLES

\section{Resumen}

Este estudio presenta un análisis de la investigación y de la producción en el área de didáctica, en el período de 2004 a 2010, en tres Programas de Postgrado en Educación pertenecientes al sur de Brasil, tomadas como estudios de casos. Surgió del análisis de importantes estudios precedentes que mostraban un vacío en el campo teórico-científico de la ciencia didáctica. La información recopilada nos llevó a la conclusión de que los estudios sobre 
didáctica no son referencia dentro de las líneas de la propia área. Se investiga y se produce mucho en el campo investigativo y en la dimensión de los fundamentos, pero las cuestiones sobre la enseñanza de la didáctica en cuanto disciplina académica, así como las formas y maneras de realizar, desde el punto de vista metodológico, el proceso de enseñanza-aprendizaje, casi no está siendo objeto de interés.

\section{Palabras clave}

Didáctica; Investigación y producción intelectual; Programas de Postgrado en Educación

Recebido em dezembro, 2012

Aceite para publicação em abril, 2013

i Curso de Fisioterapia, Universidade Federal do Triângulo Mineiro, Brasil

ii Programa de Pós-graduação em Educação, Universidade de Uberaba, Brasil

Toda a correspondência relativa a este artigo deve ser enviada para: Letícia Pimenta, Curso de Fisioterapia - UFMT, Rua Capitão Domingos, 309, Bairro Abadia, CEP 38025-010, Uberaba, MG, Brasil. E-mail: leticiabmcosta@hotmail.com 